\title{
Enhanced angiogenesis and reduced infarct size by vascular endothelial growth factor $D$ is not translated to behavioral outcome in a rat model of ischemic stroke
}

\author{
Pavel Yanev $^{1,2}$; Jukka Jolkkonen ${ }^{2,3 *}$; Kari J. Airenne ${ }^{1}$; Seppo Ylä-Herttuala ${ }^{1}$; Thomas Wirth ${ }^{1}$ \\ ${ }^{1}$ Department of Molecular Medicine and Biotechnology, A. I. Virtanen Institute for Molecular Sciences, University of Eastern \\ Finland \\ ${ }^{2}$ Institute of Clinical Medicine - Neurology, University of Eastern Finland \\ ${ }^{3}$ Brain Research and Rehabilitation Center Neuron, Kortejoki, Kuopio
}

\begin{abstract}
Vascular endothelial growth factors (VEGF) induce angiogenesis in experimental stroke models. Robust angiogenic response by VEGF, however, initially creates leaky vessels leading to edema, which may compromise functional recovery. The aim of the present work was to develop adenoviral and baculoviral gene delivery of VEGF-D, a novel member of the VEGF family, to enhance long-term angiogenesis and functional recovery in a photothrombotic model of stroke in rats. Treatment effects were assessed by histology and behavioral testing. The lesion size in the adeno-VEGF-D ${ }^{\Delta N \Delta C}(p<0.01)$ and adeno-VEGF-D $(p<0.05)$ groups was substantially reduced compared to vehicle controls. The short form of VEGF-D significantly increased the number of newly formed vessels in the medial $(p<0.001)$ and lateral cortex $(p<0.05)$ compared to vehicle controls. BaculoVEGF-D $\mathrm{D}^{\Delta N \Delta C}$ treated rats showed significant effect in the medial cortex $(p<0.01)$. The limb placing test showed transient impairment in all virus treated groups compared to the vehicle group at the acute phase 2 and 4 days after operation $(p<0.05)$. The cylinder test revealed a significant limb-use asymmetry in all ischemic animals at day 7, 14 and 21 after ischemia, which was not affected by VEGF-D treatment. In conclusion, viral mediated gene transfer of VEGF-D induced angiogenesis and reduced infarct size, which were, however, not translated to improved functional outcome in the stroke model used.
\end{abstract}

Keywords: Therapeutic vascular growth; VEGF-D $\Delta \mathrm{N} \Delta \mathrm{C}$; cerebral ischemia; neuroprotection; rat.

\section{Introduction}

Cerebral ischemia remains one of the main causes of death, which is surpassed only by heart disease and cancer. The World Health Organization estimates that in 2002 there were over 20.5 million strokes worldwide, 5.5 million of which were fatal. More than $50 \%$ of stroke patients are left with a motor disability and stroke causes more loss of quality-adjusted life years (QALY) than any other disease in the western countries (Donnan et al. 2008). The current aging population will result in a dramatic increase in these numbers in the next two decades.

Stroke has long been considered untreatable and there is no effective drug therapy to help stroke patients during the acute phase except thrombolysis, which however is available only for a small fraction of patients. A different approach for helping stroke pa- tients is to promote functional recovery. Various degrees of spontaneous recovery following weeks or months after an ischemic event are observed in clinical practice and have been related to brain repair mechanisms such as neuronal sprouting, neurogenesis and angiogenesis (Martinez-Vila et al. 2005). Stimulating the formation of new blood vessels opens a new horizon for neurorestoration that aims to enhance brain perfusion, rescuing hypoxic neurons and promoting plasticity and neurological recovery (Chen and Chopp 2006).

Angiogenesis is induced following cerebral ischemia through a variety of growth factors including vascular endothelial growth factor (VEGF), basic fibroblast growth factor (bFGF), and hepatocyte growth factor (HGF) (Ruiz de Almodovar et al. 2009; Shibuya 2009; Storkebaum et al. 2004). All members of the VEGF

\section{* Correspondence should be sent to:}

Dr. Jukka Jolkkonen, Institute of Clinical Medicine - Neurology, University of Eastern Finland, P. O. Box 1627, Yliopistonranta 1 C, 70211 Kuopio, Finland. Tel: +358-40-3552519; FAX +358-17-162048; Email: Jukka.Jolkkonen@uef.fi 
family exert their effects by binding to tyrosine kinase receptors (VEGFR) on the cell surface. Particularly, VEGF-A is a powerful mediator to increase angiogenesis and neovascularization by binding to its primary receptor VEGFR-2 (Tammela et al. 2005). However, vessels induced by VEGF-A overexpression are leaky, which leads to edema or hemorrhage, that may compromise functional recovery (Jolkkonen et al. 2007; Yu et al. 2007). Thus, other members of the VEGF family such as VEGF-D may be safer for therapeutic angiogenesis after stroke.

VEGF-D is a secreted glycoprotein that induces both angiogenesis and lymphangiogenesis. It consists of a central domain, containing binding sites for VEGFR-2 and VEGFR-3, and $\mathrm{N}$ - and $\mathrm{C}$-terminal propeptides (Achen et al. 1998). The natural cell product of VEGF-D is a homodimer of the full-length form that can be proteolytically processed to remove the propeptides into VEGF-D ${ }^{\Delta N \Delta C}$ (Brockington et al. 2004; Sun et al. 2003). The mature form of VEGF-D has many times greater affinity for VEGFR-2 binding than the unprocessed one (McColl et al. 2007). While proteolytically processed VEGF-D has high affinity for binding to both VEGFR-2 and VEGFR-3, the fulllength VEGF-D binds with high affinity only to VEGFR-3.

The aim of the present study was to evaluate the angiogenic potential of VEGF-D, a member of the VEGF gene family, after differential transduction of the brain by adenoviral and baculoviral gene delivery, in a photothrombotic model of stroke in rats. Delayed expression of VEGF-D and particularly its short processed form was expected to improve the formation of functional and stable blood vessels, which translates to behavioral improvement.

\section{Methods}

\subsection{Animals}

Eighty-four male Wistar rats (6 months, 385-503 g) were used in the study. The animals had free access to food and water and were housed in individual cages in a temperature-controlled environment $\left(20 \pm 1^{\circ} \mathrm{C}\right)$ with lights on from 7.00 to $19.00 \mathrm{~h}$. Experimental procedures were conducted in accordance with the European Community Council directives 86/609/EEC and the study was approved by the Ethics Committee of the University of Eastern Finland and the Provincial Government of Kuopio.

\subsection{Cortical photothrombosis}

Cortical photothrombosis was induced by focusing light to the sensorimotor cortex in Rose Bengal treated rats (Watson et al. 1985). Briefly, the rats were anesthetized with $5 \%$ halothane in $30 \% \mathrm{O}_{2} / 70 \%$ $\mathrm{N}_{2} \mathrm{O}$ and placed in a stereotactic frame. The anesthesia was maintained during the operation with $1-2 \%$ halothane delivered by a nose mask and the body temperature was kept at $37{ }^{\circ} \mathrm{C}$ by a rectal probe and heating pad. The skull was exposed and a cold white light (Olympus, Denmark) with a $4 \mathrm{~mm}$ aperture was positioned onto the exposed skull $0.5 \mathrm{~mm}$ anterior to the bregma and $3.7 \mathrm{~mm}$ lateral to the midline over the right motor cortex. The photochemical dye Rose Bengal (Sigma) was infused into the femoral vein via a microinjection pump within $2 \mathrm{~min}(20 \mathrm{mg} / \mathrm{kg})$, after which the light was turned on for $10 \mathrm{~min}$. The skull surface temperature was monitored with a probe placed between the skull and the light source, and kept constant by cool air flow. Sham-operated animals were treated similarly, but the light was not turned on. The rats were removed from the frame, sutured, and allowed to wake up in an incubator $\left(32^{\circ} \mathrm{C}\right)$ before being returned to their home cages.

\subsection{Vector preparation and characterization}

Adenovirus. Replication-deficient human clinicalgrade E1- partial E3-deleted first-generation adenoviruses encoding human VEGF-D ${ }^{\Delta N \Delta C}$ and lacZ under the cytomegalovirus (CMV) promoter were constructed by homologous recombination and produced in 293 cells as described previously (Hiltunen et al. 2000; Laitinen et al. 1998; Mäkinen et al. 2002).

Baculovirus. All entry clones were completely sequenced to verify the sequences before cloning of VEGF-D ${ }^{\Delta N \Delta C}$ into a pBVboostFGII expression vector using the BVboost system LR-reaction (Laitinen et al. 2005). Avidin displaying baculoviruses (Räty et al. 2004) encoding for VEGF-D ${ }^{\Delta N \Delta C}$ (BAAVI-VEGF-D ${ }^{\Delta N \Delta C}$ ) were generated by using an improved Bac-to-Bac method (Airenne et al. 2003). For the Baculo-lacZ virus, a nuclear targeted $\beta$-galactosidase $\left(\beta_{\mathrm{nt}}-\mathrm{Gal}\right)$ cassette with a CMV promoter was inserted into the Stul site of transfer vector pFASTBac1 (pFB) (Gibco $\mathrm{BRL}$, Life Technologies), generating plasmid pFBCMV- $\beta_{\mathrm{nt}}$ (Airenne et al. 2000). Purification, concentration, and titration of viral particles were performed as described previously (Airenne et al. 2000). Virus preparations were tested for sterility and analyzed for lipopolysaccharide and mycoplasma contamination.

\subsection{Gene transfer}

After photothrombotic operation a burr hole was drilled and $10 \mu$ of viral suspensions (Adeno-VEGF-D $(n=10)$, Adeno-VEGF-D ${ }^{\Delta N \Delta C}(n=13)$, Adeno-LacZ $(n=10)$, Baculo-VEGF- $D^{\Delta N \Delta C}(n=15)$, Baculo-LacZ $(n=14)$ ) containing $2 \times 10^{10}$ p.f.u/ml were injected into the left ventricle (AP: $-0.8 \mathrm{~mm}, \mathrm{~L}: 1.5 \mathrm{~mm}, \mathrm{~V}: 3.5 \mathrm{~mm}$ ) at a rate $0.1 \mu \mathrm{l}$ per minute. The needle was withdrawn after 25 minutes of injection. Control animals received the same amount of saline.

\subsection{Behavioral testing}

-2 -

J Exp Stroke Transl Med (2010) 3(2): 1-12

Society for Experimental Stroke (www.s4es.org) 
The behavioural tests selected for the study are sensitive to detect treatment effects. The animals were tested before operation and on postoperative days 2 , $4,7,14$ and 21. Behavioural testing was carried out by a person blind to treatment.

Limb-placing test. The limb-placing test was used to assess the sensorimotor integration of fore- and hindlimb responses to tactile and proprioceptive stimulation (De Ryck et al. 1989; Jolkkonen et al. 2000). The test has seven limb placing tasks, which are scored: 2 points, the rat performs normally; 1 point, the rat performs with a delay (> $2 \mathrm{sec}$ ) and/or incompletely and 0 points, the rat does not perform normally. The both sides of the body are tested. In the first task the rat is suspended $10 \mathrm{~cm}$ above the table surface. Non-lesioned rats stretch both forelimbs towards the table. On the second task the rat is held facing towards the table, resting its forelimbs on the table edge. The forelimb is gently pulled down, from the table, and subsequent retrieval and limb placement is checked. Non-lesioned rats replace both limbs on the table. The third task is the same as the second, except that the rat is not able to see the table or make vibrissal contact, since the head is held upward at a $45^{\circ}$ angle. The rats are next placed along the table edge to check the lateral placing of the fore- (the fourth task) and hindlimbs (the fifth task). The limbs are pulled down, as described in task 2, and limb retrieval is scored accordingly. In the sixth task the rat are placed with their rear end at the edge of the table, with the hindlimbs resting on the table edge. The hindlimbs, 1 at a time, are gently pulled down and from the table. If necessary, retrieval of the $\operatorname{limb}$ to the original resting place on the table edge can be stimulated by pushing the animal towards the table edge. In the seventh task the rat is placed at the table edge, facing away from the table surface. The forelimbs of the rat are placed on the edge of the table, and the rat is gently pushed from behind toward the edge. Injured rats cannot keep their grip and the injured limb slips off the edge.

Cylinder test. The cylinder test was used to assess imbalances between the impaired and non-impaired forelimb use (Schallert and Woodlee 2005). For the test, the rat is placed in a transparent cylinder ( $\varnothing 20$ $\mathrm{cm}$ ) and videotaped during the light part of the light:dark cycle before operation and at postoperative days 7,14 , and 21 . A mirror was placed at $45^{\circ}$ angle beneath the cylinder so that behavior could be filmed from below the cylinder. Exploratory activity for 1 to 3 min was analyzed by using a video recorder with slow motion capabilities. The number of contacts by both forelimbs and by either the impaired or nonimpaired forelimb was counted. The cylinder score for the impaired forelimb was calculated as: (impaired forelimb $+1 / 2 \times$ both forelimbs)/(total contacts) $\times 100 \%$.

\subsection{Immunohistochemistry}

Rats were perfused transcardially 21 days after operation with $0.9 \% \mathrm{NaCl}$ followed by $4 \%$ paraformaldehyde in $0.1 \mathrm{M}$ phosphate buffer, $\mathrm{pH}$ 7.4. The brains were removed from the skulls, postfixed, and cryoprotected. Frozen sections $(35 \mu \mathrm{m})$ were cut with a microtome and stored in a cryoprotectant tissuecollection solution at $-20^{\circ} \mathrm{C}$. Platelet-endothelial cell adhesion molecule-1 (PECAM-1) was stained as a marker for blood vessels from five randomly selected rats in each experimental group. The sections were pretreated for 30 minutes with hot $\left(85^{\circ} \mathrm{C}\right)$ citrate buffer after which the sections were transferred to a solution containing the primary antibody (rabbit antiPECAM-1 at 1:1000, Santa Cruz) and Tris-buffered saline with $5 \%$ normal goat serum (NGS) and $0.5 \%$ Triton X-100 (TBS-T). Following 18 hours of incubation in this solution on a shaker table at room temperature $\left(20^{\circ} \mathrm{C}\right)$ in the dark, the sections were rinsed three times in $5 \%$ NGS and TBS-T and transferred to a solution containing the secondary antibody (goat anti-rabbit*biotin at 1:500, Vector). After 2 hours, the sections were rinsed three times with $2 \%$ NGS and TBS-T and transferred to a solution containing mouse ExtrAvidin $®$ (Sigma) for 1 hour, and then incubated for approximately 3 minutes with $\mathrm{Ni}$-enhanced diaminobenzidine.

\subsection{Evaluation of neovascularization}

In order to quantify angiogenesis after cortical photothrombosis, images (x 20 magnification) of the cortex lateral and medial the lesion and striatum were acquired using Olympus BX40 microscope and Olympus digital camera DP50-CU and image acquisition software Viewfinder (Pixera Corporation). Images were digitally processed using Adobe $^{\circledR}$ Photoshop $^{\circledR}$ CS3. In each section the corresponding areas from the contralateral hemisphere were used as a control (Fig. 1). PECAM-1 immunoreactivity in each image was determined using two image analysis systems. Images were analyzed initially with ImageJ, a Javabased image processing program, but in order to get reliable values, custom made software was adopted. It incorporated the color segmentation method in a MathWorksTM Matlab ${ }^{\circledR} 7.5$ environment, modified for 3 channels so that vessels could be better distinguished from the background. In comparison, ImageJ uses binary basis for quantification. The values corresponding to total vessel coded color areas were averaged and expressed as the mean percentage of stained vessels per $100 \mu \mathrm{m}^{2}$.

\subsection{Assessment of infarct volumes}

Nissl-stained sections were used for assessment of infarct volumes. Estimation of the infarct area in the cortex was performed on the sections digitalized under $a \times 20$ objective (Olympus BX40) using a 3-CCD - 3 - 
color video camera (Sony DXC-970MD) interfaced with an image analysis system (MCID, Imaging Research). The image of each section was taken as $1280 \times 1024$ matrix of calibrated pixel units. The digital image was then displayed on a video screen and the lesion area was manually outlined. The total volume was calculated by multiplying the infarct area by the distance between the sections and summing together the volumes for each brain.

\subsection{Statistical analysis}

SPSS software was used for statistical analyses. Statistical differences in infarct volumes in the cortex and blood vessel counts between groups were analyzed using one-way analysis of variance (ANOVA) followed by a post hoc test (Scheffe) when necessary. Differences in the limb-placing scores between experimental groups were analyzed by Kruskal-Wallis followed by Mann-Whitney U-tests. Cylinder data for the overall group effect were analyzed using ANOVA for repeated measures. Comparisons between the groups were then made using one-way ANOVA followed by a post hoc test (Scheffe).

\section{Results}

\subsection{Survival of rats}

The cortical photothrombosis is generally characterized by a very low mortality. In the present experiment only two rats had to be sacrificed due to complications during the recovery period. There was no significant difference in body weight between shamoperated and ischemic control rats or between treated ischemic rats and vehicle controls.

\subsection{Ischemic lesion}

The cortical infarct was located in the frontal cortex (Fr1 and Fr2) and extended to the corpus callosum with no evidence of damage to the underlying striatum (Fig. 1A). Resolution of the necrotic tissue resulted in the formation of a partly fluid-filled cyst by the end of the 3 week follow-up period. In the current settings the average size of the cortical lesion in vehicle controls was $33.6 \pm 2.4 \mathrm{~mm}^{3}$. The infarct sizes in the adeno-VEGF-D ${ }^{\Delta N \Delta C}\left(20.4 \pm 6.1 \mathrm{~mm}^{3}\right)(p<0.01)$ and adeno-VEGF-D $\left(22.4 \pm 5.5 \mathrm{~mm}^{3}\right) \quad(p<0.05)$ groups were substantially reduced compared to vehicle controls (Fig. 2). Baculo-VEGF-D ${ }^{\triangle N \Delta C}$ group (26.9 \pm 2.4 $\mathrm{mm}^{3}$ ) was not different from vehicle controls.
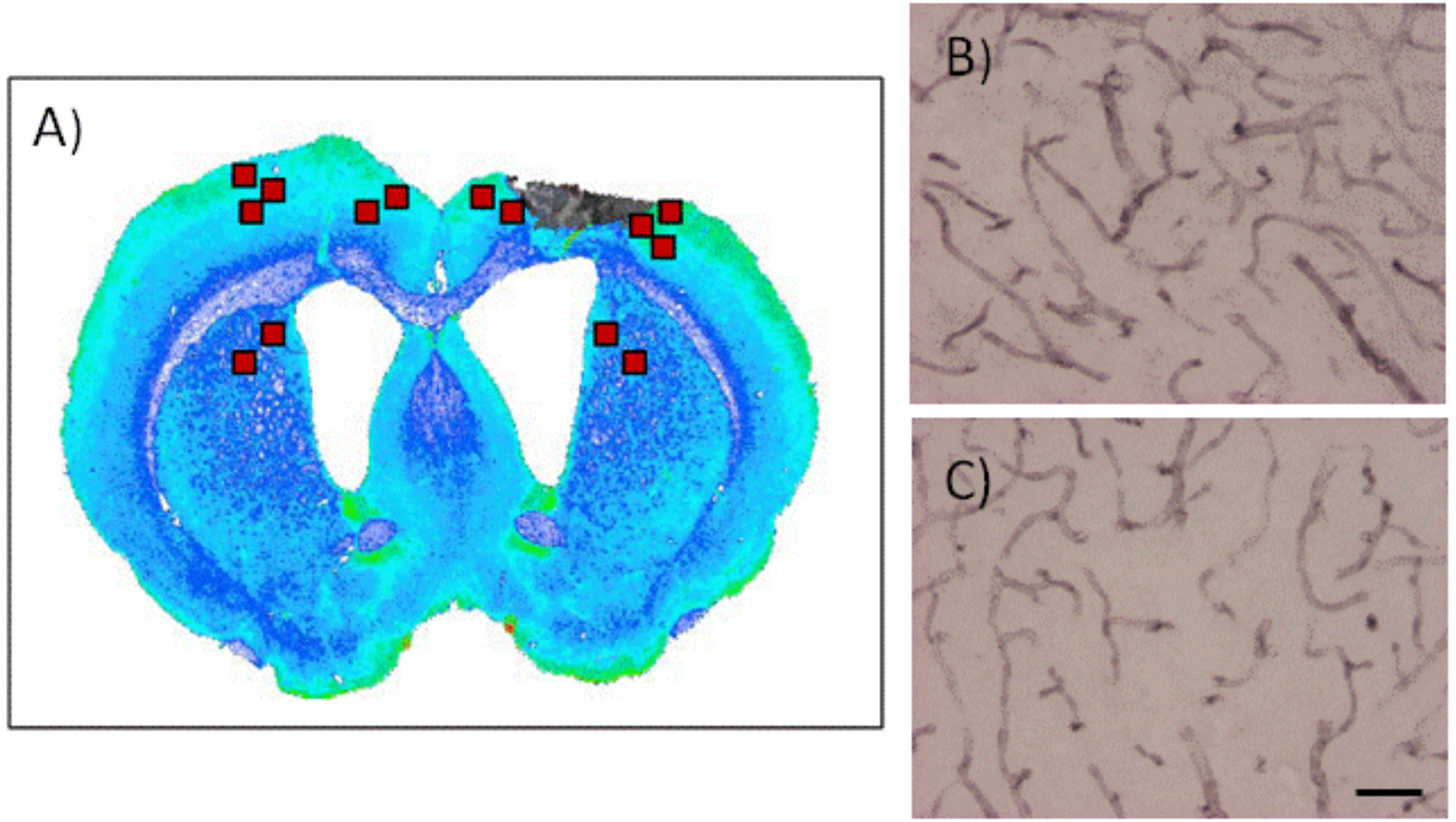

Fig. 1. Pseudo-colored image from the rat subjected to cortical photothrombosis and representation of areas in the ipsilateral and contralateral cortex selected for the analysis of angiogenesis (A). A micrograph of PECAM staining in the ipsilateral (B) and contralateral medial cortex (C) from the Ad-VEGF- $D^{\Delta N \Delta C}$ treated rat. Scale bar $100 \mu \mathrm{m}$. 


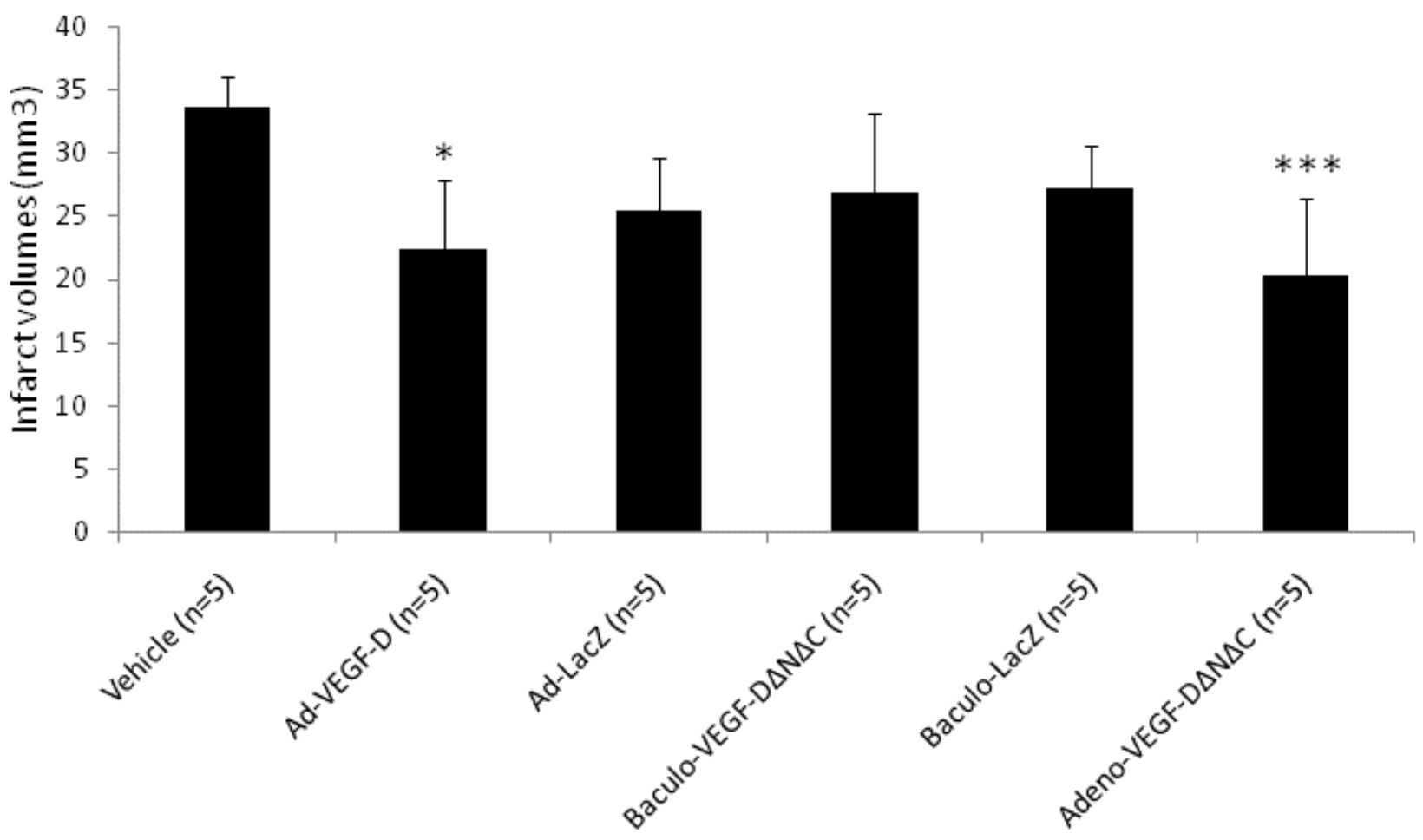

Fig. 2. Infarct volumes $\left(\mathrm{mm}^{3}\right)$ in rats subjected to cortical photothrombosis followed by treatment with viral delivered VEGF-D. Data are mean \pm S.D. The number of rats in each group is in parenthesis. Statistical significance: ${ }^{*} p<0.05 ;{ }^{* *} p<0.001$ (from vehicle).

\subsection{Quantification of angiogenesis}

In order to determine whether intraventricular administration of different forms of VEGF-D enhances cerebral angiogenesis, photothrombotic ischemic rats were treated with the viral constructs 30 minutes after ischemia. It was expected that delayed production of VEGF-D would surpass the peak of brain excitotoxicity and edema and show therapeutic effect on angiogenesis. Previous studies with VEGF-A have showed a peak of newly formed vessels 12 days after administration of viral vectors (Dellian et al. 1996). For vessel quantification, 7 distinct non-overlapping areas were selected from the ipsilateral hemisphere and the corresponding areas from the contralateral hemisphere (Fig. 1A). The ratio of the two was then compared to that of the control group. The program used for vessel density quantification is novel in the sense that it distinguishes vessels much more accurately from the background staining as it incorporates the 3 color segmentation mechanism as compared for example to conventional NIH Image ${ }^{\circledR}$ software for Image Analysis (National Institutes of Health).

Compared to the vehicle controls, the short form of VEGF-D ${ }^{\Delta N \Delta C}$ significantly increased the number of newly formed vessels in the medial $(p<0.001)$ and lateral cortex $(p<0.05)$ (Fig. 3). Interestingly, baculoVEGF-D ${ }^{\Delta N \Delta C}$ did show significant effect only in the medial cortex $(p<0.01)$. The other vector construct, adeno-VEGF-D, which is a far less potent angiogenic factor than the proteolytically processed VEGF-D did not increase the angiogenic response significantly. 


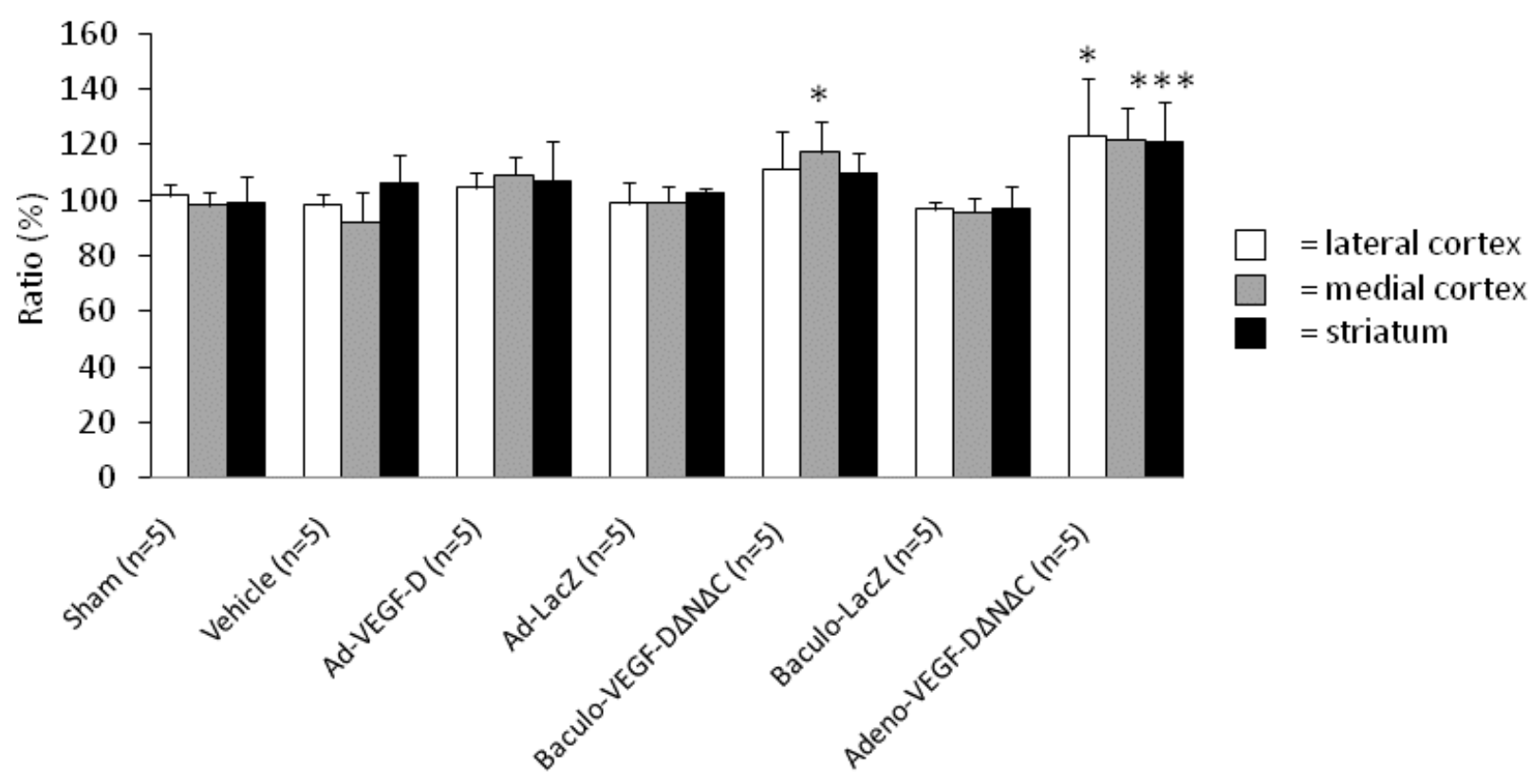

Fig. 3. Angiogenesis as assessed by PECAM staining in the ipsilateral and contralateral cortex and striatum in rats subjected to cortical photothrombosis followed by treatment with viral delivered VEGF-D. The ratio between the ipsilateral and contralateral cortex was calculated for statistical analysis. Data are mean \pm S.D. The number of rats in each group is in parenthesis. Statistical significance: ${ }^{\star} p<0.05 ;{ }^{* \star} p<0.01 ;{ }^{* \star} p<0.001$ (from vehicle).

\subsection{Behavioral testing}

To determine whether VEGF-D and consequential angiogenesis improve functional recovery after photothrombotic stroke, the behavioral performance of rats was tested during the 21 day follow-up. Rats in all the ischemia operated groups showed a significant sensorimotor impairment at the acute phase 2 days after stroke. Partial spontaneous recovery was observed in all groups.

The limb placing test showed impaired performance in all virus treated rats compared to vehicle controls at 4 days $(p<0.05)$, however, this was transient and no difference was detected at 21 days except in the case of baculo-VEGF-D ${ }^{\Delta N \Delta C}$ (Fig. 4), which indicates that this was most likely due to some adverse effects of the viral treatment at the peak of gene expression (e.g., inflammatory response). All ischemic groups showed a reduced use of the impaired forelimb in the cylinder test at day 7, 14 and 21 after the infarct (Fig. 5). ANOVA for repeated measures showed a significant group effect $(p<0.01)$ and a significant time $x$ group interaction $(p<0.01)$. These were explained by the difference between sham-operated rats and ischemic groups. 


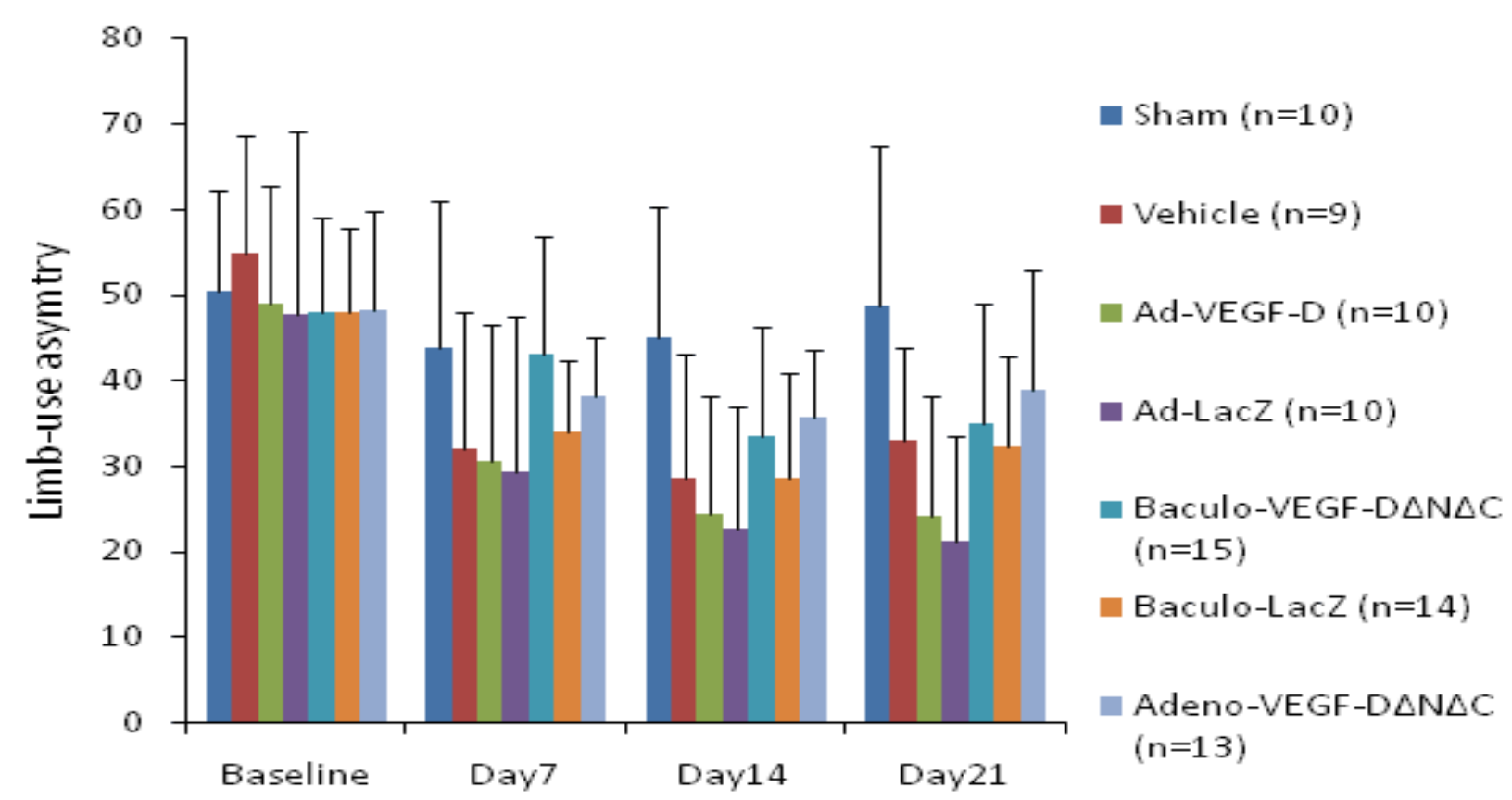

Fig. 4. Forelimb use during lateral exploration in rats subjected to cortical photothrombosis followed by treatment with viral delivered VEGF-D. The score was calculated as (impaired forelimb use $+1 / 2$ both forelimb use/total contacts) $\times 100 \%$. Data are mean \pm S.D. The number of rats in each group is in parenthesis. There were no statistically significant differences among ischemic rats.

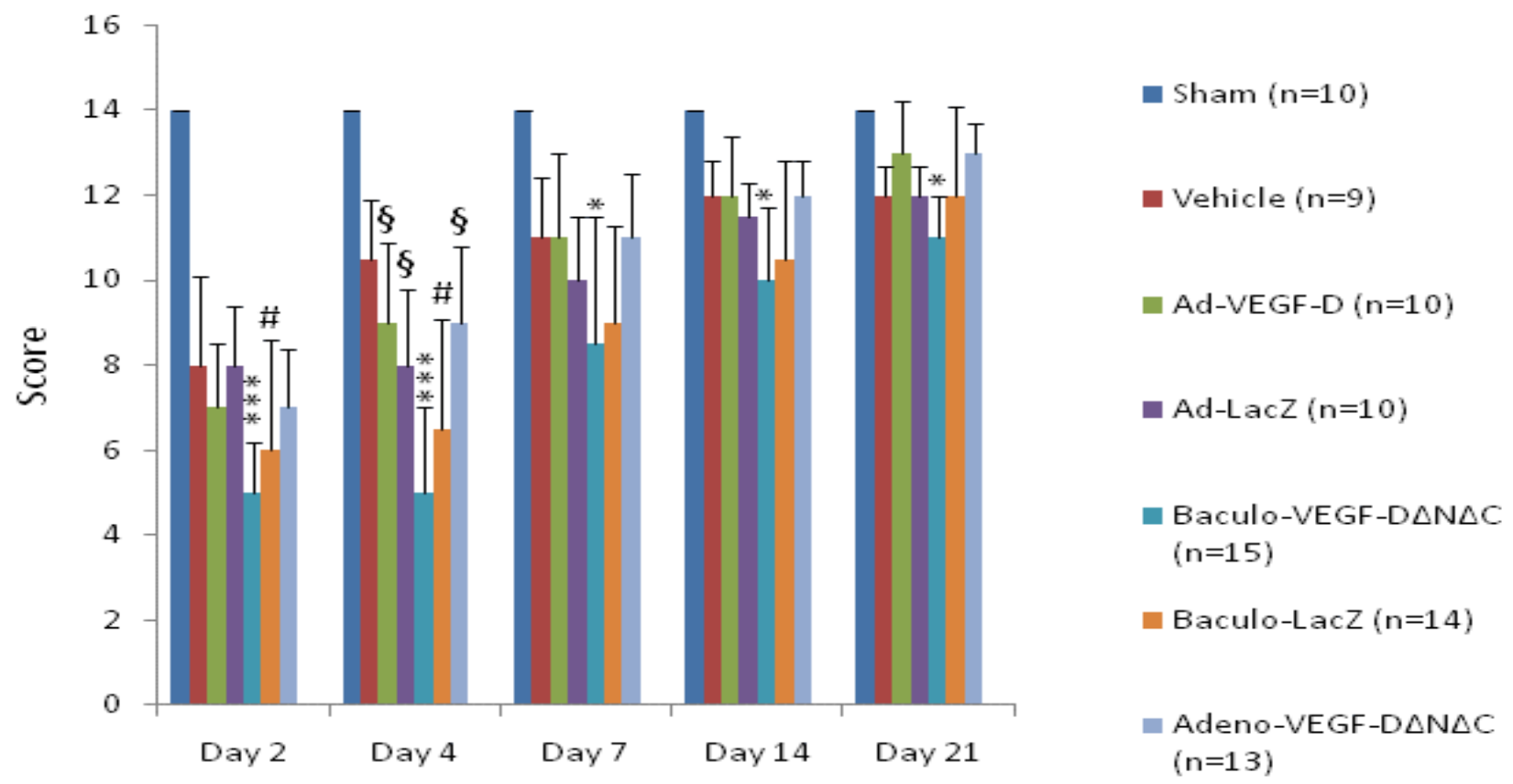

Fig. 5. Limb-placing scores in rats subjected to cortical photothrombosis followed by treatment with viral delivered VEGF-D. Initial severe impairment is followed by spontaneous recovery during the follow-up. Data are median \pm S.D. The number of rats in each group is in parenthesis. Statistical significance: ${ }^{*} p<0.05 ;{ }^{* \star *} p<0.001$ 
(Baculo-VEGF- D ${ }^{\Delta N \Delta C}$ vs. vehicle); \#p< 0.05 (Baculo-LacZ vs. vehicle); $\S p<0.05$ (Ad-VEGF-D/Ad-LacZ/AdVEGF- $D^{\Delta N \Delta C}$ vs. vehicle).

\section{Discussion}

In the present study we evaluated the therapeutic potential of VEGF-D after ischemic stroke.

To our knowledge, there are no studies in the literature that have evaluated the therapeutic potential of VEGF-D induced angiogenesis in experimental stroke. Several studies have suggested that VEGF-D and particularly its processed form are powerful angiogenic factors in muscle and heart tissues. Adenoviral VEGF-D ${ }^{\Delta N \Delta C}$ gene transfer in pig myocardium has been shown to induce a dose dependent protein production and promote angiogenic effects much more diffusely throughout the myocardial tissue as compared to VEGF-A $A_{165}$ (Rutanen et al. 2004). This difference could be attributed to the soluble and freely diffusible VEGF-D ${ }^{\Delta N \Delta C}$ while VEGF-A $A_{165}$ has good matrix-binding properties. In a rabbit hindlimb ischemia model, VEGF-D ${ }^{\Delta N \Delta C}$ produces the strongest angiogenic effect among the members of the VEGF family (Rissanen et al. 2003). VEGF-D ${ }^{\Delta N \Delta C}$ upregulates VEGFR-2 and $\alpha_{v} \beta_{3}$ integrin expression in endothelial cells, which suggest that angiogenic signaling mechanisms are very similar to those of VEGF-A (Ferrara 1999). With a higher dose of both VEGF$D^{\triangle N \triangle C}$ and VEGF-A there is substantial edema formation. However, VEGF-A induces greater edema as compared to VEGF-D ${ }^{\triangle N \Delta C}$ after intramyocardial gene transfer (Rutanen et al. 2004), and might therefore be better as a pro-angiogenic candidate in therapeutic use.

\subsection{Different transduction profiles of adenovirus and baculovirus in the CNS}

Easy production and high gene deliver efficiency into immune-privileged sites such as those of the CNS make adenovirus and baculovirus positive candidates for a therapeutic delivery of VEGF-D. Moreover, they have different transduction patterns in the brain (Lehtolainen et al. 2002). Baculoviruses were found to transduce the cuboid epithelium of the choroid plexus very efficiently $(76.8 \pm 14 \%)$ whereas adenoviruses showed a marked preference for the ventricular ependymal cell lining $(71.4 \pm 9 \%)$ and corpus callosum $(83.5 \pm 11 \%)$. Transgene expression with adeno/baculovirus starts as early as $6 \mathrm{~h}$ after transduction and reaches peak at 3-6 days depending on the construct and the vector (Airenne et al. 2009; Russel 2000). Both viral vector types lead also to expression of the transgene in the brain microvessel endothelial cells (Lehtolainen et al. 2002). In accordance, a difference in the angiogenic response between adenovi- rus and baculovirus was detected also in the present study.

\subsection{Angiogenesis and VEGF-D}

Here we demonstrated that adenovirus and baculovirus induced expression of VEGF-D ${ }^{\Delta N \Delta C}$ significantly enhances cerebral angiogenesis ipsilaterally in a rat photothrombotic stroke model. The virus itself did not enhance angiogenesis, as there was no difference in vessel density ratios compared to the sham and vehicle treated animals. The advantage of transducing the ependymal cell lining and the choroid plexus by adenovirus and baculovirus, respectively, is that VEGF-D is a soluble protein and will be secreted into the cerebrospinal fluid. The vectors were not injected into the ischemic core, because the cells are affected by necrotic death and extensive edema a few hours after the onset of ischemia (Siesjö 1981; Taoufik and Probert 2008). There have been many studies in which the method of application of the therapeutic agent has been chosen to be direct parenchymal administration close to the lesion (Gunnett and Heistad 2001). Although this was a feasible delivery approach especially in the photothrombotic model of stroke where the position of infarcted tissue is more or less constant, we expected that forced overproduction of VEGF-D would increase the burden on the already compromised brain environment in the periinfarct site.

In our paradigm, VEGF-D protein disseminates through the cerebrospinal fluid circulation in the brain. Abundant VEGF-D delivery may also cause angiogenesis in remote areas of the brain and possibly in the contralateral hemisphere. Nevertheless elevated levels of VEGFs, within a certain range, are not sufficient to produce a significant angiogenic response in the non-affected brain tissue. The formation of stable new blood vessels requires activation of brain repair mechanisms around the lesion as well as in some parts of the ipsilateral hemisphere functionally connected with the injury. For example, numerous developmental factors are re-expressed in the peri-infarct regions, which promote neurogenesis, synaptogenesis and angiogenesis (Chopp and Li 2006). In this sense the density of VEGFR-2, which plays the major role in angiogenesis, increases within $48 \mathrm{~h}$ postischemia (Marti et al. 2000) and this is predominantly on ischemic neurons (Beck et al. 2002) and astrocytes (Choi et al. 2007). Growth factors such as VEGF-A stimulate further overexpression of the VEGFR-2 (Wang et al. 2005).

It is interesting to point out that while VEGFR-3, the primary receptor for long unprocessed form of VEGF$\mathrm{D}$, was long believed to be responsible only for lym- 8 - 
phangiogenesis, new reports have emerged showing the compensatory function of VEGFR-3 signaling in angiogenesis (Tammela et al. 2008). Studies show that signaling through it promotes proliferation and survival of endothelial cells in culture (Goldman et al. 2007). Moreover, blocking this receptor appears to most prominently affect the number of sprouting and branching points of new blood vessels. In the experiments on tumor anti-angiogenesis, it became evident that VEGFR-3 can drive angiogenesis even in conditions where VEGFR-2 is targeted therapeutically to suppress its angiogenic signals. In our case the long form of VEGF-D did not produce a significant angiogenic response, but it reduced infarct size.

\subsection{Reduction of infarct size by VEGF-D}

The production of VEGF-D starts at $6 \mathrm{~h}$ post transduction, yet the formation of the first new stable blood vessels takes at least a few days, a time window surpassing the rapid period in which the necrotic core expands (Chen et al. 1994). Thus, it is likely that the smaller lesion size in VEGF-D ${ }^{\triangle N \Delta C}$ treated rats is a result of a mechanism other than true neuroprotection. One possibility is that VEGF-D reduces the brain injury by protecting the vascular system in the periinfarct site against ischemia. Indeed, VEGF-A has an important role in maintaining or restoring the integrity of endothelial cells (Radisavljevic et al. 2000). A second possibility is that VEGF-D has a potent growth and survival effect on neurons and vascular cells similar to VEGF-A (Chavakis et al. 2002; Nishijima et al. 2007; Rosenstein et al. 2003). Although there are some differences in the reports of the temporal course of gene induction as well as the identification of expressing cells, VEGF-A is increased after injury in the peri-infarct region as early as 1-3 $\mathrm{h}$ (Beck and Plate 2009; Hermann and Zechariah 2009) and persists for up to 1 month after ischemia (Hai et al. 2003). VEGFR-1 and VEGFR-2 expression is also elevated in neurons and endothelial cells of penumbral areas beginning at $3 \mathrm{~h}$, peaking at $24 \mathrm{~h}$, and persisting for more than 7 days after ischemia (Brockington et al. 2004). The VEGFR-2 signaling pathway that results in CAMP response element-binding protein (CREB) phosphorylation is the shared mechanism that underlies the preconditioning-mediated protection of neurons and vascular endothelial cells in the neonatal rat brain (Lee et al. 2009). A further study on the matter suggested that VEGFR-2/CREB signaling is critical for VEGF-A-mediated protection in neurons and cerebral vascular endothelial cells (Lee et al. 2010). This could also contribute to our results. Inflammatory response as indicated by the increase of body temperature in all virus treated rats (data not shown), might also alter lesion size. And last, reduction of infarct volume may be due to an enhanced removal process of debris due to angiogenesis induced by VEGF-D treatment.

\subsection{Functional recovery}

This is the first report on the effect of VEGF-D on functional recovery after focal cerebral ischemia in rats. Our study indicates that VEGF-D ${ }^{\Delta N \Delta C}$-induced peri-lesional angiogenesis is not obviously translated to functional recovery as assessed by sensorimotor tests. The recent literature on the possible therapeutic effects of VEGF in stroke is mixed (Manoonkitiwongsa et al. 2004; Yang et al. 2010). Different experimental models, timing of treatment, administration route, doses and outcome measures are likely to contribute to this. Inflammation caused by viral vectors may compromise beneficial treatment effects in the present study. In addition, in all the groups there is already a spontaneous functional recovery. Because the current model produces only mild motor function impairment, it may be that the VEGF-D treatment is not sufficient to further boost the existing recovery mechanisms. Those effects on neurological outcome could be much better demonstrated in a model with more severe brain infarction such as MCAO. Another limitation of the current model is that the photothrombotic lesion does not leave enough salvageable brain tissue where the angiogenic factor could exert its restorative potential fully. Indeed, the penumbral area here is substantially smaller, and although there is expansion of the necrotic core, it is not as profound as in the model of MCAO (Watson et al. 1995; Witte et al. 2000). Another speculation for the behavioral test results could be that the timing of increased angiogenesis and of increased vessel density may not be sufficient for a robust amelioration of neurological deficit. Angiogenesis is elevated in the peri-infarct area in the beginning of the recovery process, but it may need much more time to promote neurogenesis and plasticity in a functionally relevant manner. Although this seems a possible explanation, prolonged expression of angiogiogenic factors such as VEGF-D and VEGF-A could also be harmful. A more advanced approach to the problem would utilize Tet-controlled expression, where the transgene is expressed only in the presence of doxycycline (Gossen et al. 1995).

\section{Conclusion}

Here, we have tested the restorative potential of VEGF-D through angiogenesis in the area surrounding an evolving brain infarct in an experimental stroke model. Increased angiogenesis and reduced infarct size were observed by viral gene delivery of VEGF-D, but this was not translated to behavioral outcome during the three week follow-up. Thus, in the acute and subacute phases after stroke, angiogenesis may - 9 - 
have predominantly other functions such as removal of edema and/or necrotic tissue in the ischemic border zone rather than promoting direct functional improvement. Further research is needed to understand the mechanisms and the therapeutic value of angiogenic factors in enhancing functional recovery after stroke.

\section{Acknowledgment}

This study was supported by Finnish Academy, the Finnish Funding Agency for Technology and Innovation and Ark Therapeutics Ltd.

\section{Conflict of Interest}

None

\section{References}

Achen MG, Jeltsch M, Kukk E, Mäkinen T, Vitali A, Wilks AF, Alitalo K, Stacker S A. (1998) Vascular endothelial growth factor $D$ (VEGF-D) is a ligand for the tyrosine kinases VEGF receptor 2 (Flk-1) and VEGF receptor 3 (Flt-4). Proc Natl Acad Sci USA 95:548-553.

Airenne KJ, Hiltunen MO, Turunen MP, Turunen AM, Laitinen $\mathrm{OH}$, Kulomaa MS, Ylä-Herttuala S. (2000) Baculovirus-mediated periadventitial gene transfer to rabbit carotid artery. Gene Ther 7:1499-504.

Airenne KJ, Peltomaa E, Hytönen VP, Laitinen $\mathrm{OH}$, Ylä-Herttuala S. (2003) Improved generation of recombinant baculovirus genomes in Escherichia coli. Nucleic Acids Res 31:e101.

Airenne KJ, Mähönen AJ, Laitinen Olli H, YläHerttuala S. (2009) Baculovirus-mediated gene transfer: An emerging universal concept. In: Templeton NS, editor. Gene and Cell Therapy. Therapeutic Mechanisms and Strategies, New York: Taylor and Francis. p. 263-291.

Beck H, Acker T, Püschel AW, Fujisawa H, Carmeliet $\mathrm{P}$, Plate KH. (2002) Cell type-specific expression of neuropilins in an MCA-occlusion model in mice suggests a potential role in post-ischemic brain remodeling. J Neuropathol Exp Neurol 61:339350.

Beck H, Plate KH. (2009) Angiogenesis after cerebral ischemia. Acta Neuropathol 117:481-96.

Brockington A, Lewis C, Wharton S, Shaw PJ. (2004) Vascular endothelial growth factor and the nervous system. Neuropathol Appl Neurobiol 30:427446.
Chavakis E, Dimmeler S. (2002) Regulation of endothelial cell survival and apoptosis during angiogenesis. Arterioscler Thromb Vasc Biol 22:88793.

Chen HH, Chien CH, Liu HM. (1994) Correlation between angiogenesis and basic fibroblast growth factor expression in experimental brain infarct. Stroke 25:1651-7.

Chen J, Chopp M. (2006) Neurorestorative treatment of stroke: cell and pharmacological approaches. NeuroRx 3:466-473.

Choi JS, Kim HY, Cha JH, Choi JY, Park SI, Jeong $\mathrm{CH}$, Jeun SS, Lee MY. (2007) Upregulation of vascular endothelial growth factor receptors Flt-1 and Flk-1 following acute spinal cord contusion in rats. J Histochem Cytochem 55:821-830.

Chopp M, Li Y. (2006) Transplantation of bone marrow stromal cells for treatment of central nervous system diseases. Adv Exp Med Biol 585:49-64.

Dellian M, Witwer BP, Salehi HA, Yuan F, Jain RK. (1996) Quantitation and physiological characterization of angiogenic vessels in mice: effect of basic fibroblast growth factor, vascular endothelial growth factor/vascular permeability factor, and host microenvironment. Am J Pathol 149:59-71.

De Ryck M, Van Reempts J, Borgers M, Wauquier A, Janssen PA. (1989) Photochemical stroke model: flunarizine prevents sensorimotor deficits after neocortical infarcts in rats. Stroke 20:1383-90.

Donnan GA, Fisher M, Macleod M, Davis SM. (2008) Stroke. Lancet 371:1612- 23.

Ferrara N. (1999) Molecular and biological properties of vascular endothelial growth factor. J Mol Med 77:527-43.

Goldman J, Rutkowski JM, Shields JD, Pasquier MC, Cui Y, Schmökel HG, Willey S, Hicklin DJ, Pytowski B, Swartz MA. (2007) Cooperative and redundant roles of VEGFR-2 and VEGFR-3 signaling in adult lymphangiogenesis. FASEB $\mathrm{J}$ 21:1003-12. Erratum (2007) FASEB J 21:1942.

Gossen M, Freundlieb S, Bender G, Müller G, Hillen W, Bujard H. (1995) Transcriptional activation by tetracyclines in mammalian cells. Science 268:1766-9.

Gunnett CA, Heistad DD. (2001) The future of gene therapy for stroke. Curr Hypertens Rep 3:36-40.

Hai J, Li ST, Lin Q, Pan QG, Gao F, Ding MX. (2003) Vascular endothelial growth factor expression and angiogenesis induced by chronic cerebral hypoperfusion in rat brain. Neurosurgery 53:963970 
Hermann DM, Zechariah A. (2009) Implications of vascular endothelial growth factor for postischemic neurovascular remodeling. J Cereb Blood Flow Metab 29:1620-43.

Hiltunen MO, Laitinen M, Turunen MP, Jeltsch $\mathrm{M}$, Hartikainen J, Rissanen TT, Laukkanen J, Niemi M, Kossila M, Häkkinen TP, Kivelä A, Enholm B, Mansukoski $\mathrm{H}$, Turunen AM, Alitalo K, YläHerttuala S. (2000) Intravascular adenovirusmediated VEGF-C gene transfer reduces neointima formation in balloon-denuded rabbit aorta. Circulation 102:2262-2268.

Jolkkonen J, Puurunen K, Rantakömi S, Härkönen A, Haapalinna A, Sivenius J. (2000) Behavioral effects of the alpha(2)-adrenoceptor antagonist, atipamezole, after focal cerebral ischemia in rats. Eur J Pharmacol 400:211-9.

Jolkkonen J, Jokivarsi K, Laitinen T, Gröhn O. (2007) Subacute hemorrhage and resolution of edema in Rose Bengal stroke model in rats coincides with improved sensorimotor functions. Neurosci Lett 428:99-102.

Mäkinen $\mathrm{K}$, Manninen $\mathrm{H}$, Hedman M, Matsi P, Mussalo H, Alhava E, Ylä-Herttuala S. (2002) Increased vascularity detected by digital subtraction angiography after VEGF gene transfer to human lower limb artery: a randomized, placebocontrolled, double-blinded phase II study. Mol Ther 6:127-33.

Laitinen M, Mäkinen K, Manninen $\mathrm{H}$, Matsi $\mathrm{P}$, Kossila M, Agrawal RS, Pakkanen T, Luoma JS, Viita H, Hartikainen J, Alhava E, Laakso M, Ylä-Herttuala S. (1998). Adenovirus-mediated gene transfer to lower limb artery of patients with critical leg ischaemia. Hum Gene Ther 9:1481-1486.

Laitinen $\mathrm{OH}$, Airenne KJ, Hytönen VP, Peltomaa E, Mähönen AJ, Wirth T, Lind MM, Mäkelä KA, Toivanen PI, Schenkwein D, Heikura T, Nordlund HR, Kulomaa MS, Ylä-Herttuala S. (2005) A multipurpose vector system for the screening of libraries in bacteria, insect and mammalian cells and expression in vivo. Nucleic Acids Res 33:e42.

Lee HT, Chang YC, Tu YF, Huang CC. (2009) VEGFA/VEGFR-2 signaling leading to cAMP response element-binding protein phosphorylation is a shared pathway underlying the protective effect of preconditioning on neurons and endothelial cells. J Neurosci 29:4356-4368.

Lee HT, Chang YC, Tu YF, Huang CC. (2010) CREB activation mediates VEGF-A's protection of neurons and cerebral vascular endothelial cells. J Neurochem, in press
Lehtolainen $\mathrm{P}$, Tyynelä $\mathrm{K}$, Kannasto J, Airenne $\mathrm{KJ}$, Ylä-Herttuala S. (2002) Baculoviruses exhibit restricted cell type specificity in rat brain: a comparison of baculovirus- and adenovirus-mediated intracerebral gene transfer in vivo. Gene Ther 9:1693-9.

Manoonkitiwongsa PS, Schultz RL, McCreery DB, Whitter EF, Lyden PD. (2004) Neuroprotection of ischemic brain by vascular endothelial growth factor is critically dependent on proper dosage and may be compromised by angiogenesis. $\mathrm{J} \mathrm{Ce}-$ reb Blood Flow Metab 24:693-702.

Marti HJ, Bernaudin M, Bellail A, Schoch H, Euler M, Petit E, Risau W. (2000) Hypoxia-induced vascular endothelial growth factor expression precedes neovascularization after cerebral ischemia. Am J Pathol 156:965-976

Martínez-Vila E, Irimia P. (2005) Challenges of neuroprotection and neurorestoration in ischemic stroke treatment. Cerebrovasc Dis 20 Suppl 2:148-58.

McColl BK, Paavonen K, Karnezis T, Harris NC, Davydova N, Rothacker J, Nice EC, Harder KW, Roufail S, Hibbs ML, Rogers PA, Alitalo K, Stacker SA, Achen MG. (2007) Proprotein convertases promote processing of VEGF-D, a critical step for binding the angiogenic receptor VEGFR-2. FASEB J 21:1088-98.

Nishijima K, Ng YS, Zhong L, Bradley J, Schubert W, Jo N, Akita J, Samuelsson SJ, Robinson GS, Adamis AP, Shima DT. (2007) Vascular endothelial growth factor-A is a survival factor for retinal neurons and a critical neuroprotectant during the adaptive response to ischemic injury. Am J Pathol 171:53-67.

Radisavljevic Z, Avraham H, Avraham S. (2000) Vascular endothelial growth factor up-regulates ICAM-1 expression via the phosphatidylinositol 3 $\mathrm{OH}$-kinase/AKT/Nitric oxide pathway and modulates migration of brain microvascular endothelial cells. J Biol Chem 275:20770-4.

Rissanen TT, Markkanen JE, Gruchala M, Heikura T, Puranen A, Kettunen MI, Kholová I, Kauppinen RA, Achen MG, Stacker SA, Alitalo K, YläHerttuala S. (2003) VEGF-D is the strongest angiogenic and lymphangiogenic effector among VEGFs delivered into skeletal muscle via adenoviruses. Circ Res 92:1098-106.

Rosenstein JM, Mani N, Khaibullina A, Krum JM. (2003) Neurotrophic effects of vascular endothelial growth factor on organotypic cortical explants and primary cortical neurons. J Neurosci 23(35):11036-44. 
Ruiz de Almodovar C, Lambrechts D, Mazzone M, Carmeliet P. (2009) Role and therapeutic potential of VEGF in the nervous system. Physiol Rev 89:607-48.

Russell WC. (2000) Update on adenovirus and its vectors. J Gen Virol 81:2573-604.

Rutanen J, Rissanen TT, Markkanen JE, Gruchala M, Silvennoinen $P$, Kivelä A, Hedman A, Hedman M, Heikura T, Ordén MR, Stacker SA, Achen MG, Hartikainen J, Ylä-Herttuala S. (2004) Adenoviral catheter-mediated intramyocardial gene transfer using the mature form of vascular endothelial growth factor-D induces transmural angiogenesis in porcine heart. Circulation 109:1029-35.

Räty JK, Airenne $\mathrm{KJ}$, Marttila AT, Marjomäki V, Hytönen VP, Lehtolainen $P$, Laitinen $\mathrm{OH}$, Mähönen AJ, Kulomaa MS, Ylä-Herttuala S. (2004) Enhanced gene delivery by avidindisplaying baculovirus. Mol Ther 9:282-91.

Schallert T, Woodlee MT. (2005) Orienting and placing. In: Whishaw IQ Kolb B, editors. The behavior of the laboratory rat. A handbook with tests. New York: Oxford University Press; 2005. p. 129-140.

Shibuya M. (2009) Brain angiogenesis in developmental and pathological processes: therapeutic aspects of vascular endothelial growth factor. FEBS J 276:4636-43.

Siesjö BK. (1981) Cell damage in the brain: a speculative synthesis. J Cereb Blood Flow Metab 1:155-85.

Storkebaum E, Lambrechts D, Carmeliet P. (2004) VEGF: once regarded as a specific angiogenic factor, now implicated in neuroprotection. Bioessays 26:943-54.

Sun Y, Jin K, Xie L, Childs J, Mao XO, Logvinova A, Greenberg DA. (2003) VEGF-induced neuroprotection, neurogenesis, and angiogenesis after focal cerebral ischemia. J Clin Invest 111:18431851.

Tammela T, Enholm B, Alitalo K, Paavonen K. (2005) The biology of vascular endothelial growth factors. Cardiovasc Res 65:550-63.
Tammela T, Zarkada G, Wallgard E, Murtomäki A, Suchting S, Wirzenius $M$, Waltari $M$, Hellström $M$, Schomber T, Peltonen R, Freitas C, Duarte A, Isoniemi $\mathrm{H}$, Laakkonen $\mathrm{P}$, Christofori $\mathrm{G}$, YläHerttuala S, Shibuya M, Pytowski B, Eichmann A, Betsholtz C, Alitalo K. (2008) Blocking VEGFR-3 suppresses angiogenic sprouting and vascular network formation. Nature 454:656-60.

Taoufik E, Probert L. (2008) Ischemic neuronal damage. Curr Pharm Des 14:3565-73.

Wang Y, Kilic E, Kilic U, Weber B, Bassetti CL, Marti $\mathrm{HH}$, Hermann DM. (2005) VEGF overexpression induces post-ischaemic neuroprotection, but facilitates haemodynamic steal phenomena. Brain 128:52-63.

Watson BD, Dietrich WD, Busto R, Wachtel MS, Ginsberg MD. (1985) Induction of reproducible brain infarction by photochemically initiated thrombosis. Ann Neurol 17: 497-504.

Watson BD, Dietrich WD, Prado R. Concepts and techniques of experimental stroke induced by cerebrovascular photothrombosis. In: Ohnishi ST, Ohnishi T, editors. Central nervous system: trauma research techniques. Boca Raton: CRC Press; 1995. p. 169-194.

Witte OW, Bidmon H-J, Schiene K, Redecker C, Hagemann G. (2000) Functional differentiation of multiple perilesional zones after focal cerebral ischemia. J Cereb Blood Flow Metab 20:11491165.

Yang JP, Liu HJ, Liu XF. (2010) VEGF promotes angiogenesis and functional recovery in stroke rats. J Invest Surg 23:149-55.

Yang ZJ, Bao WL, Qiu MH, Zhang LM, Lu SD, Huang YL, Sun FY. (2002) Role of vascular endothelial growth factor in neuronal DNA damage and repair in rat brain following a transient cerebral ischemia. J Neurosci Res 70:140-149.

Yu SW, Friedman B, Cheng Q, Lyden PD. (2007) Stroke-evoked angiogenesis results in a transient population of microvessels. J Cereb Blood Flow Metab 27:755-63. 